\title{
Trauma to scrotal hernia: a rare cause of bowel rupture
}

\section{SMHMK Senanayake ${ }^{1}$}

A 60-year old male with right scrotal hernia was assaulted with a brick on the right groin leading to swelling of right scrotum. He had been treated for scrotal contusion at the local hospital and died on the third day.

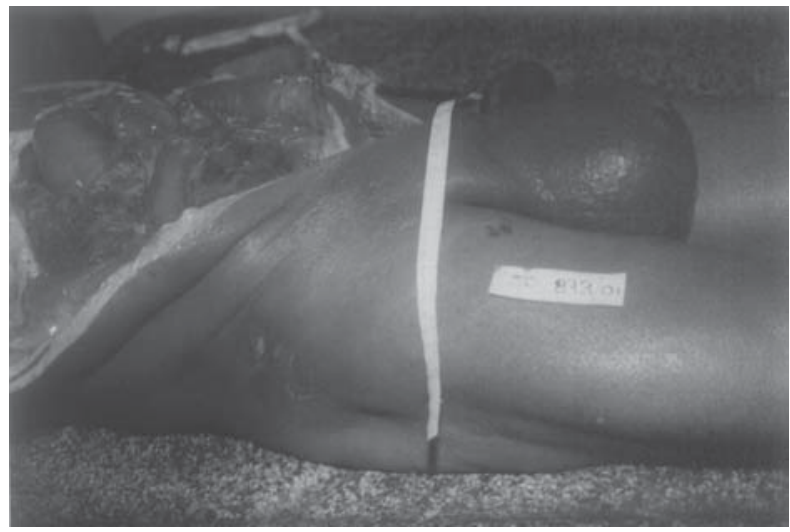

Figure1. Postmortem findings showing swollen scrotum and peritonitis.

Postmortem examination: Externally two abrasions on right groin, red and swollen scrotum with circumference of $35 \mathrm{~cm}$ and postmortem loss of epidermis on bottom of the scrotum were seen. Internally congested viscera, fibrinous adhesions of bowel, enlarged soft spleen, pulmonary oedema, yellow swollen renal cortices and perforation $(1 \mathrm{~cm})$ in anti-mesenteric border of the distal ileum one foot proximal to the appendix with a black margin were noted (Figure 1). Cause of death was decided as septicaemia due to peritonititis following rupture of the ileum, compatible with blunt trauma.

\section{Discussion}

Following are the causes of bowel rupture in trauma victims [1]: (a) open abdominal injuries such as stabs, firearm injuries and bomb blasts, (b) closed abdominal injuries producing shock waves, shearing force, crushing of bowel between weapon and spine, tear by fractured bone, raised intraluminal pressure within a closed loop, (c) injuries to mesenteric arteries leading to thrombosis, then bowel infarction leading to delayed perforation, and (d) jumps from height causing a sudden jolt in an inguinal hernia [2].

In this case, trauma had caused crushing of small bowel between the blunt weapon and the underlying pubic bone. Abrasions are due to a corner of the brick. The original injury was legally classified as fatal in the ordinary course of the nature.

\section{References}

1. Saukko P. Chest and abdominal injuries. In: Knight B, ed. Knight's Forensic Pathology. 3rd ed. London: Arnold, 2000: 230-1.

2. Brown SP. Abdominal trauma. In: Brian WE, Brown SP, eds. Hamilton Bailey's Emergency Surgery. 13th ed. London: Arnold, 2000: 446-63. 